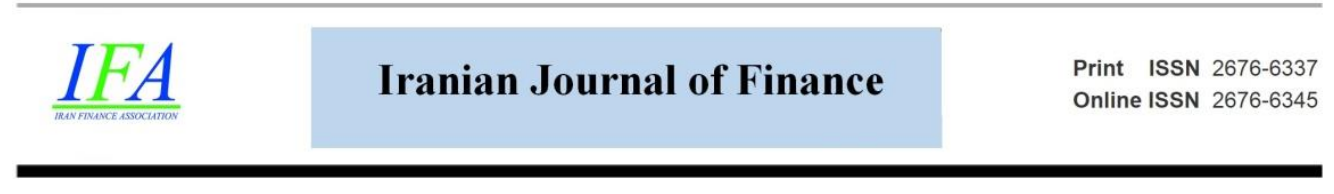

\title{
The Effect of Using Fair Value Approach on Performance Prediction in Investment Companies
}

\author{
Roohollah Seddighi* \\ *Corresponding Author, Assistant Prof., Department of Accounting, Faculty of \\ Management and Accounting, Allameh Tabataba'i University, Tehran, Iran. (Email: \\ e_seddighi@yahoo.com)
}

\section{Ali Ghasemi}

MSc, Department of in Accounting, Faculty of Management and Accounting, Allameh Tabataba'i University, Tehran, Iran. (Email: Ali.Ghasemi@Live.com)

\section{Mohammad Mehdi Momenzadeh}

MA in Auditing, Faculty of Management and Accounting, Allameh Tabataba'i University, Tehran, Iran. (Email: Momenzadeh2000@yahoo.com)

Document Type: Original Article

Received: 2020/07/14

Accepted: 2021/02/14

2021, Vol. 5, No. 2. 1-20

Published: 2021/02/22

\begin{abstract}
One of the most fundamental factors in pricing and evaluating the performance of companies is their profitability and profit is used as a basis for predicting the future performance of companies. Therefore, an accurate profit prediction is really crucial and decisive. There are various approaches to this prediction. The first approach would be calculating profit according to accounting standards by using historical cost and the second, calculating profit according to fair value. In this circumstance, this question arises that whether fair values are used instead of historical cost, would it lead to a more accurate and better prediction of the company's future performance?

The purpose of this study is to investigate the effect of using the fair value in calculating profits on the performance of investment companies with the help of benchmarking international financial reporting standards for small and medium-sized units.

This research uses the data of 95 companies listed on the Tehran Stock Exchange, whose activity is an investment, from 2015 through 2019 and compares the predictability of fair value-based profits with the profit based on accounting standards in predicting the company's operating cash flows and future profits. The data is first collected in Excel software, then the research
\end{abstract}


variables are calculated and finally, research models are tested and analyzed by Eviews10.

The results show that fair value-based profit has no greater ability to predict the performance of investment companies in comparison to profit based on Iranian accounting standards.

Keywords: Fair value, Performance prediction, Quality, International Financial Reporting Standards, Small and Medium-sized Entities.

\begin{tabular}{cc}
\hline DOI: 10.30699/ijf.2021.126884 & Publisher: Iran Finance Association \\
Copyright: author(s) & Type of License: Creative Commons License (CC-BY 4.0)
\end{tabular}

\section{Introduction}

Financial reporting is one of the mechanisms that can improve the performance of capital markets. Users of financial information expect large and active companies in the capital market to provide high quality financial and reporting information because if the quality of companies' financial reporting increases, the value of the company is expected to rise as well. High-quality reporting can greatly alleviate investor concerns about internal information, and public dissemination of quality information by management will reduce the information asymmetry between management and other users. Studies have shown that reduced information asymmetry in turn results in lower capital costs, reduced information risk, increased predictability of cash flows, improved company valuation, and finally increased liquidity of stocks (Tabrizi Nezhad Malek Mohammad, 2016). People need financial information to make decisions, and accounting is one of the sources of financial information supply. Conceptual Framework for Financial Reporting addresses the role of financial information and its usefulness in individuals' decision making. According to the IFRS Foundation, the objective of general-purpose financial reporting is to provide financial information about the reporting entity that is useful to existing and potential investors, lenders and other creditors in making decisions relating to providing resources to the entity. Those decisions involve decisions about:

(a) Buying, selling or holding equity and debt instruments;

(b) Providing or settling loans and other forms of credit; or

(c) Exercising rights to vote on, or otherwise influence, management's actions that affect the use of the entity's economic resources (IFRS 2018). 
Biddle, Hilary \& Verdi (2009) define the quality of reporting as follows: "We define financial reporting quality as the precision with which financial reporting conveys information about the firm's operations, in particular its expected cash flows, that inform equity investors" (Biddle, Hillary \& Verdi 2009).

A number of studies, such as Ball, Li \& Shivakumar (2015) have pointed out that the emphasis of international standards on valuation has made accounting figures less useful. Preparing and developing a set of high-quality accounting standards does not necessarily lead to high-quality financial reporting as part of the quality of reporting relates to management incentives and regulatory requirements. Fox, Hannah, Helliar \& Veneziani (2013) compare the relationship between accounting figures and rules and culture in Italy and England. First, in terms of legal systems, Italy is a civil-law country; its accounting standards are subservient to its Civil Code, and its accounting regulations tend to be incorporated into its national laws. The researchers argue that these standards are not compulsory but they have an integrative and interpretative function with respect to the provisions of the law. In contrast, in the legal system of the common-law countries, such as the United Kingdom, it appears that reporting standards are less compliant with laws and regulations. Firms in the UK rely on capital markets to raise money, and so financial reporting is needed to ensure transparency and market efficiency. In Italy, however, companies are mostly family-owned and financed through the banking system. Therefore, creditors, too, need corporate financial statements. In terms of culture, the UK has traditionally relied on accrual accounting as a key concept, while prudence has traditionally dominated in Italy (De George, Li \& Shivakumar 2016). In the meantime, the mission of the International Standards Formation Board is to develop a globally accepted, high-quality set of standards. Despite its surface simplicity, the execution and fulfillment of the mission are absolutely difficult. This is partly because all words must be carefully selected. Global accounting standards provide the required conditions for global financial reporting. Yet, they are not sufficient. In fact, without a single set of standards, one cannot hope for equal financial reporting around the world (Barth, 2008). Since the issuance of IFRSs for SMEs in 2009 by the International Accounting Standards Board (IASB) for companies which do not have public accountability, 86 countries have required or permitted the use of this set of standards for their SMEs so far. Some countries, however, have either rejected or not applied the set (IFRS Foundation 2018). It should be noted that EU member states and certain countries such as Canada, Australia, China, Japan and India have still not adopted IFRS for SMEs, and countries 
such as Russia and Iran are currently under consideration this set of standards (IFRS Foundation 2018).

Table 1. Status of SMEs standard acceptance in the world

\begin{tabular}{|c|c|}
\hline Status & $\begin{array}{c}\text { Number of } \\
\text { countries }\end{array}$ \\
\hline The number of countries that have allowed or required these standards. & 86 \\
\hline $\begin{array}{c}\text { The number of countries currently under consideration the set of } \\
\text { standards. }\end{array}$ & 11 \\
\hline The number of countries that have never accepted these standards. & 69 \\
\hline Total & 166 \\
\hline
\end{tabular}

Before the IASB published reporting standards for SMEs, countries used either national standards or the full version of IFRS for SMEs. According to IASB, small and medium-sized standards facilitate the access of these entities to the international financial resources by enhancing reporting quality as well as assimilating financial information (Bonito \& Pais, 2018).

Academic studies have long been focused on the prediction of earnings provided by management. This was due to the unreliability of the predictions. In fact, the US Securities and Exchange Commission prohibited companies from offering predictions (Hiler, 1987), but the views changed over time. Today, the majority of recent studies show that earnings prediction by management provides more information to investors than other accounting information (Bozanic, Roulstone \& Van Buskirk, 2018). One of the purposes of financial statements is to provide information on the financial position, financial performance and cash flows that are useful to a wide range of users. Today, studies focus on the relevance of fair value accounting and assign a higher priority to accounting predictability than reliability (Yao, Percy, Stewart $\& \mathrm{Hu}, 2015)$. IFRS, for the most part, have used fair value accounting to measure assets and liabilities. Since the global financial crisis, fair value accounting in the banking industry has been highly debated. The current debate about fair value accounting versus historical cost price accounting concerns the contrast between relevance and reliability. One of the general objectives of financial reporting, in accordance with the IASB, is to "provide information on the financial status, financial performance and cash flows of an economic entity which is beneficial to a wide range of users in their economic decision makings". 
Several studies have examined the usefulness of accounting information in predicting future cash flows. Nevertheless, a limited number of studies have examined the predictability of fair value information in the prediction of future earnings and cash flows. Proponents of fair value maintain that fair value's ability to predict is due to its power to reflect the current market status. Fair values of certain financial instruments have predictive value for future cash flows and earnings generated from those assets because unrealized gains or losses accumulated over time can translate into realized cash flows and income through the sale of such assets (Bratten, Causholli \& Khan, 2014). Therefore, fair value may be related to the future performance of the economic entity (Evans, Hodder \& Hopkins, 2014). Furthermore, recent studies of banks illustrate that management can use fair value for smoothing earnings; thereby enhancing earnings sustainability and earnings information value (Yao et al. 2015).

There are criticisms concerning the negative side of the impact of fair value on the ability of earnings to predict future performance. Opponents of fair value accounting argue that fair value prediction is much more volatile than historical cost price accounting prediction and that it makes it difficult to predict the future. Moreover, fair value can be subjectively determined by management, especially when capital markets are illiquid. Measurement errors can exert a reverse impact on reliability and relevance (Yao et al. 2015). The theoretical literature on performance prediction demonstrates that company's performance is a function of fair value-based earnings (Yao et al. 2015), company size (Pervan \& Visic, 2012), company's asset growth (Shu, Bradstock \& Xu, 2013). The ratio of cash earnings per share (Shu, Broadstock, $\& \mathrm{Xu}, 2013)$ and the company's life (Pervan, Pervan \& Curak, 2017).

\section{Research Background}

Rahmani and Taheri (2017) compared the impact of cost price and fair value of facilities on credit loss of Iranian banks. Using the cost price data included in the financial statements and estimating the fair value of the facilities of 23 Iranian banks in the period of 2007-2015, they examined the effect of fair value and historical cost price on the banks' credit loss. Discounted cash flow model provided by the US Federal Reserve was used to estimate the fair value of banking facilities. Results of the study showed that in the Iranian banking network, the cost price of facilities can better predict banks' credit loss compared to fair value. Radi and Pesian (2016) examined the impact of fair value in financial reporting on the earnings predictability concerning future 
earnings and cash flows in companies listed on the Tehran Stock Exchange. Results of the study indicated that applying fair value in financial reporting has an impact on the earnings predictability in predicting future cash flows and earnings. Radi, Azimi, and Seyedzadeh (2015) examined the impact of fair value use in financial reporting on the prediction of future earnings in companies listed on the Tehran Stock Exchange. In fact, the study sought to find out the impact of applying fair value accounting on financial reporting, and enhancing the firm's ability to predict future earnings. Research results demonstrated that applying fair value in financial reporting exerts an impact on the company's ability to predict future earnings. Senan (2019) in his paper investigated the ability of earnings and cash flows to predict future cash flows. As the results of his study indicated, earnings have a better ability to predict future operating cash flow. These results are consistent with the FASB's claim that earnings are better able to predict cash flows. Kang and Yoo (2019), studied investors' perceptions of the predictability of fair value valuations. The results revealed that investors consider the predictive power of fair value to be more than the predictability of accounting-based performance. Boina and Macedo (2018), in their paper, investigated the predictability of accruals before and after applying the IFRS in Brazil. In their paper, the ability of discretionary and non-discretionary accruals in predicting future cash flows was analyzed and evaluated. The results showed that before applying international standards, discretionary and non-discretionary accruals had a negative and significant relationship with the prediction of future cash flows. These items also had a significant positive impact on the prediction of future cash flows after applying international standards. Bratten, Causholli \& Khan (2016) examined the usefulness of fair value in predicting banks' future earnings. A sample of bank holding companies was selected, and the impact of comprehensive earnings and its components on the banks' earnings for the next one and two years was investigated. The results showed that fair value improves earnings' predictability in predicting earnings and future cash flows for the next one and two years. It also increases its predictability if fair value enjoys a higher level of reliability. In general, the results of the study were in line with the approaches of the FASB and the IASB. Marra (2016), in the article under the title "The Pros and Cons of Fair Value Accounting in a Globalized Economy: A Never Ending Debate", presented a summary of articles in this area, and concluded that fair value has a better relationship with the information needs regarding globalization and access to international economies. Yao, Percy, Stewart \& $\mathrm{Hu}$ (2015) examined the usefulness of fair value in enhancing the predictability of operating earnings in banks. The study which was based on samples from banks in 24 countries (excluding the US) from 2009 to 2012 
concluded that first, by increasing fair value use in financial instruments in the balance sheet, current earnings' power in predicting future earnings and cash flows would increase, and second, choosing one of the fair value hierarchies also influences the predictability of future cash flows. Furthermore, there is a significant relationship between the factors of organizational structure in countries and the predictability of fair value.

Sodan (2015) examined the impact of fair value accounting on the quality of accounting earnings in Eastern European countries. The study was conducted in the banks of Eastern European countries from 2002 to 2011. According to the hypothesis of the study, Eastern European banks estimate fair value more through valuation techniques compared to developed European countries because there are no suitable markets for valuation in these countries. In fact, the lack of markets leads to poor quality of earnings due to fair value manipulation by the management. The study addressed six attributes of earnings quality, including persistence, predictability, smoothing, accruals, relevance and conservatism. The impact of fair value was examined through the earnings and loss approach, i.e. the earnings and loss of banks before and after the fair value adjustments. The results showed that as the fair value utilization increased, the quality of earnings diminished. Bratten, Causholli and Khan (2014) conducted a study entitled "Usefulness of Fair Values in Predicting Future Cash Flows and Earnings". In their study, samples of stock and non-stock banks were examined, and two methods of earnings and loss and balance sheet were used to investigate the impact of fair value. The results showed that the higher the fair value utilization in financial statements in both groups of stock and non-stock banks, the greater the earnings-driven from the predictability of future earnings and cash flows. They concluded that as the reliability of the employed fair value increases, the obtained predictability earnings escalate. The results of the study were, therefore, consistent with the approach of FASB on the usefulness and relevance of fair value. Liang \& Riedl (2014) compared fair value and cost price regarding the prediction accuracy of financial analysts. In their article, they compared real estate investment firms in the United States and the United Kingdom and examined the accuracy of the balance sheet and the predicted earnings and loss. The results indicated that for the UK companies that used the fair value method, net asset value in the predicted balance sheet was more accurate compared to the US predicted balance sheet. Also, the predictive power of earnings per share in British companies was lower due to the identification of unrealized earnings in net profit. Cantrell, McInnis \& Yust (2014) examined the impact of fair value and the cost price method in predicting credit loss. The results of the study 
demonstrated that the facilities' cost price method predicts credit loss better than the fair value method. With regard to banks' financial instruments, Blankespoor, Linsmeier, Petroni \& Shakespeare (2013) compared the fair value method with those with the less fair value used in their financial statements. The result was that when the calculated leverage ratios are under fair value, they display a greater deviation compared to the time when the fair value is lower.

\section{Research Hypotheses}

Based on the above-mentioned explanations, the hypotheses of this research are formulated as follows:

Hypothesis 1: The relationship between fair value-based current earnings and the next year's net income is stronger than the relationship between Iran's accounting standards-based earnings and the next year's net income.

Hypothesis 2: The relationship between fair value-based current earnings and next year's cash flows is stronger than Iran's accounting standards-based earnings and next year's cash flows.

\section{Research Method}

Two methods of library and field research were used to collect relevant data and information. In the library research section, the theoretical literature and research background were obtained mainly from books, internal and national articles, and internet sites while in the field study part, research data was used from the audited financial statements of companies in the Codal website (Comprehensive Database of All Listed Companies), portfolio investment information in the website, and stock price information from Tehran Stock Exchange Technology Management Company. The data was collected in Excel software, the necessary variables were calculated, and the data was analyzed through Eviews 10 software. The statistical population of the study is the subsidiary companies of the public companies whose activities involve investment, which was defined as SMEs according to international standard, and their information was available on Comprehensive Database of All Listed Companies website (Codal.ir). Out of 127 SMEs on the Codal website, 95 companies were selected as sample. The samples were studied between 2015 and 2019, and the following models were used to test the research hypotheses: 
Hypothesis 1

$\mathrm{NI}_{\mathrm{it}+1}=\beta_{0}+\beta_{1}$ EarnFV $_{\mathrm{it}}+\gamma_{1}$ Size $_{\text {it }}+\gamma_{2}$ Growth $_{\text {it }}+\gamma_{3} \operatorname{Div}_{\mathrm{it}}+\gamma_{4}$ Age $_{\mathrm{it}}+\varepsilon$

$N I_{\mathrm{it}+1}=\beta_{0}+\beta_{1} N I_{\mathrm{it}}+\gamma_{1}$ Size $_{i t}+\gamma_{2}$ Growth $_{i t}+\gamma_{3}$ Div $_{i t}+\gamma_{4}$ Age $_{i t}+\varepsilon$

Hypothesis 2

$C F_{\mathrm{it}+1}=\beta_{0}+\beta_{1}$ EarnFV $_{i t}+\gamma_{1}$ Size $_{i t}+\gamma_{2}$ Growth $_{i t}+\gamma_{3}$ Div $_{i t}+\gamma_{4} A g e_{i t}+\varepsilon$

$C F_{\text {it }+1}=\beta_{0}+\beta_{1} N I_{\text {it }}+\gamma_{1}$ Size $_{i t}+\gamma_{2}$ Growth $_{i t}+\gamma_{3}$ Div $_{i t}+\gamma_{4} A g e_{i t}+\varepsilon$

Dependent variables

$N I_{i t+1}$ Net income of the next financial year as per Iran standards

$C F_{i t+1}$ Operating cash flow of the next year, obtained from the cash flow statement

Independent variables

EarnFV $V_{i t}$ Adjusted net profit of the current financial year based on the SME standard

$N I_{i t}$ Net income of the current financial year as per Iran standards

Control variables

Size $_{i t}$ Total financial year's end-of-year assets as per Iran standards

Growth $h_{i t}$ Assets' growth rate compared to the previous financial year as per Iran standards

Div $v_{i t}$ Cash earnings divided in the financial year

Age $_{i t}$ The number of years the company has been operating since its inception.

The reason for choosing these variables as control variables were that according to the theoretical literature of performance prediction, company's performance is a function of its size (Pervan \& Visic, 2012), company's assets growth (Shu, Broadstock \& Xu, 2013), divided cash earnings ratio (Shu, Broadstock \& Xu, 2013) and company's life (Pervan, Pervan \& Curak (2017). When regression analysis is performed, in order for the estimated regression to be the Best Linear Unbiased Estimator (BLUE), there must exist a series of assumptions called classical linear regression assumptions as follows (Wooldridge, 2016): 

follows:

Number One: The population regression model should be linear, as

$y=\beta_{0}+\beta_{1} x_{1}+\beta_{2} x_{2}+\cdots+\beta_{k} x_{k}+u$

Here, linearity means that there exists a linear relationship between $\beta_{\mathrm{k}} \mathrm{s}$. That is, for example, these coefficients are not in the denominator or the power. However, if the relationship between $\mathrm{y}$ and $\mathrm{x}$ is not linear, it does not disturb the hypothesis.

Number Two: Sampling should be random. The results of the research can only be generalized to the population if the sample represents the population. Random sampling also avoids the correlation between $u_{i}$ and $x_{s}$. In other words, the disruptive component of one company is not correlated with the independent variable of the other company, and there will be no correlation between $u_{i}$ and $u_{s}$. Of course, there is no such assumption in time series because time-series do not undergo sampling and the only one-time interval is selected.

Number Three: There must be no perfect collinearity between the independent variables. In other words, there must be no precise linear relationship between the variables, and a variable must not be a fixed multiple of the other variable due to the wrongful definition of the model. For example, $x_{1}=2 x_{2}$, or a variable must not be a linear function of the other variables, for example, $x_{1}=x_{2}+x_{3}$. Also, the model may be correct, but the data may in fact have a perfect linear relationship. In other words, the size of each company is twice the company's earnings which in practice is highly unlikely to happen.

Number Four: The expected value of the disturbance component for every value of $\mathrm{x}$ must equal zero. That is:

$E\left(u \mid x_{1}, x_{2}, \ldots, x_{k}\right)=0$

This means that the disturbance component of any company must have no relation to the independent variable of the other company. This assumption holds true in time series, with the exception that the disturbance component at time t has no relation with the independent variable at any time. There is, of course, another approximate assumption that can be used instead of the above assumption which is as follows:

$E(u)=0$ and $\operatorname{Cov}\left(x_{j}, u\right)=0$ 
According to this approximate assumption, the independent variable of each company is independent of the disturbance component of the same company, and the expected value of the sum of disturbance components in the population is zero. In the time series, the disturbance component of a time is not related to the independent variable of the same time.

Number Five: In serial correlation or autocorrelation, there must be no disturbance in the components:

$\operatorname{Corr}\left(u_{t}, u_{s} \mid X\right)=0$

Number Six: For every value of $\mathrm{x}$, disturbance components have finite and equal variance:

$\operatorname{Var}\left(u \mid x_{1}, x_{2}, \ldots, x_{k}\right)=\sigma^{2}$

Number Seven: The population of disturbance components is independent of the independent variables, and has a normal distribution with the mean of zero and the variance of $\sigma^{2}$ :

$u \sim \operatorname{Normal}\left(0, \sigma^{2}\right)$

This assumption is stronger than all previous assumptions. Yet, in practice, there is no knowledge of the disturbance component distribution, and the assumption can be disregarded if the sample size is large. The assumption of normality is used only for $\mathrm{t}$ and $\mathrm{F}$ statistical tests because the sampling distribution must be normal. In panel and cross-sectional analysis, the above seven conditions must meet, and according to the Gauss-Markov theorem, if your linear regression model satisfies the first six classical assumptions, then the regression produces the BLUE. It is not necessary to meet the seventh condition that is the normal distribution of the error or disturbance component of the population, in order for the regression to be the BLUE. It is, however, required to test the hypotheses to examine the significance of the explanatory variables. It should be noted that if conditions one to four are met, the regression is still unbiased, and if the fifth and sixth conditions are also met, the regression will have the least variance to which the word "best" belongs in the Gauss-Markov theorem. According to the central limit and Gauss-Markov theorem, if the sample size is sufficiently large, there is no need for the seventh condition, and one can test the assumptions of the significance of the variables. While some sources have not mentioned the second condition, namely random sampling, the sample must represent the population, meaning that the probability of each member being selected must be equal, and the selection of one does not affect the other. Furthermore, the central limit theorem requires that members of the sample be independent, and in order to test the hypotheses, 
random sampling must be performed so as to facilitate making statistical inferences (Wooldridge, 2016). To validate the model, the classical assumptions will be investigated as follows:

1- Regarding the first condition, given that the models of this research are linear, this assumption is valid.

2- The second condition is not met because due to the limitations of the study, the sampling is not random, and is conducted non-randomly. However, given the limitations of the study, it can be assumed that random sampling characteristics are present for the study.

3- In this regard, the perfectness of the linear relationship between the independent variables must be examined.

4- It is always assumed that the expected value of the unobservable components (u) at the population level is zero. There should, however, be no correlation between the disturbance component and the independent variables, which usually cannot be investigated. But if, according to existing theories and studies, the independent variables are correctly selected, and no variable is omitted, it can be reasonably assured that there is no correlation between the disturbance component and the independent variables.

5- For this condition, too, the Durbin-Watson Test is used. Serial correlations only affect beta variance and hypotheses testing as a result, thus making the tstatistic results unrealistic in some cases. This study used amplified or modified standard error to deal with a serial correlation which is used when there is autocorrelation or heteroskedasticity of variance. The method of calculating the standard error is different from normal standard error, and as a result, autocorrelation and heterogeneity of variance do not affect it. This standard error can be used to test statistical assumptions, and the statistical assumptions' test is reliable. In this study, the Arellano model based on the White model was used which is suitable for fixed effects. This model is included in the Eviews software as White-Period.

6- Before testing this assumption, autocorrelation must be removed because otherwise, the assumption's test results will be incorrect. This can generally be examined in two ways: 1-Graph 2- heteroskedasticity variance tests (e.g. Breusch-Pagan test or White test). If there is, or is likely to be, variance autocorrelation and heteroskedasticity, amplified standard error can be used, as in assumption 5. Arellano model is used in this study.

7- Regarding the normality of the disturbance components' population, if the sample size is large, the absence of this condition does not cause any problems. 


\section{Research Findings}

The following table displays the descriptive statistics for the independent variables with one year lag:

Table 2. Descriptive statistics of the first and second hypotheses - lagged variables

\begin{tabular}{|c|c|c|c|c|c|c|}
\hline $\begin{array}{c}\text { Description / } \\
\text { Variable }\end{array}$ & $\begin{array}{c}\text { EARNFV(-1) } \\
\text { (million rials) }\end{array}$ & $\begin{array}{c}\text { NI(-1) } \\
\text { (million } \\
\text { rials) }\end{array}$ & $\begin{array}{c}\text { SIZE(-1) } \\
\text { (million } \\
\text { rials })\end{array}$ & $\begin{array}{c}\text { GROWTH(- } \\
1)\end{array}$ & $\begin{array}{c}\text { AGE(-1) } \\
\text { (year) }\end{array}$ & $\begin{array}{c}\text { DIV(-1) } \\
\text { (million } \\
\text { rials })\end{array}$ \\
\hline Mean & 350276.8 & 147664.4 & 1847246 & 0.295994 & 11.09574 & 142389 \\
\hline Median & 33140.95 & 33916.5 & 492060 & 0.069144 & 10 & 25000 \\
\hline Maximum value & 8399232 & 2820513 & 12593965 & 15.47499 & 45 & 2300000 \\
\hline Minimum value & -1809482 & -1419090 & 4328 & -0.86842 & 0 & 0 \\
\hline $\begin{array}{c}\text { Standard } \\
\text { deviation }\end{array}$ & 1107468 & 343526.9 & 2803589 & 1.172918 & 7.427616 & 305111 \\
\hline Skewness & 4.147979 & 3.178883 & 1.936632 & 7.828287 & 2.046584 & 3.569721 \\
\hline $\begin{array}{c}\text { Kurtosis } \\
\text { Number of } \\
\text { observations }\end{array}$ & 24.2822 & 22.02521 & 5.930917 & 85.61298 & 8.859755 & 17.8461 \\
\hline
\end{tabular}

\section{The first research hypothesis}

Model number 1

$N I_{\mathrm{it}+1}=\beta_{0}+\beta_{1} \operatorname{EarnFV}_{i t}+\gamma_{1}$ Size $_{i t}+\gamma_{2}$ Growth $_{i t}+\gamma_{3}$ Div $_{i t}+\gamma_{4} A g e_{i t}+\varepsilon$ (11)

The independent variables have one-year lag ( $t-1)$ :

Table 3. Results of fixed effects- Model Number 1

\begin{tabular}{|c|c|c|c|c|}
\hline Variable & Coefficient & Standard error & T- statistic & Prob. \\
\hline EARNFV & $1.92 \mathrm{E}-05$ & 0.077965 & 0.000247 & 0.9998 \\
\hline SIZE & -0.0836 & 0.053784 & -1.55442 & 0.1212 \\
\hline GROWTH & -12094.3 & 8944.453 & -1.35215 & 0.1774 \\
\hline AGE & 2226.103 & 3446.275 & 0.645945 & 0.5188 \\
\hline DIV & -0.39515 & 0.21313 & -1.85402 & 0.0648 \\
\hline C & 343777.2 & 87622.64 & 3.923383 & 0.0001 \\
\hline
\end{tabular}


Results of the Durbin-Watson Test, F statistic, coefficient of determination and adjusted coefficient of determination are as follows:

Table 4. Other results of fixed effects- Model Number 1

\begin{tabular}{|c|c|c|c|c|}
\hline Adjusted R-squared & R-squared & Prob (F-statistic) & F-statistic & Durbin-Watson \\
\hline 0.642146 & 0.735665 & 0.0000 & 7.866466 & 4.171420 \\
\hline
\end{tabular}

In this model, the coefficient of determination is $\cdot / \mathrm{V}$, so $73 \%$ of the changes in the dependent variable are explained by independent variables. Also, the pvalue of the F-statistic is zero, so regression is generally significant. Durbin Watson statistic for this model is about 4, but due to the use of Arellano covariance, this high statistic is not a problem.

The p-value for the EarnFV variable is also 0.9, so this variable is statistically meaningless.

Model number 2

$N I_{\mathrm{it}+1}=\beta_{0}+\beta_{1} N I_{\mathrm{it}}+\gamma_{1}$ Size $_{i t}+\gamma_{2}$ Growth $_{i t}+\gamma_{3}$ Div $_{i t}+\gamma_{4}$ Age $_{i t}+\varepsilon$

The independent variables have one-year lag (t-1):

Table 5. Results of fixed effects- Model Number 2

\begin{tabular}{|c|c|c|c|c|}
\hline Variable & Coefficient & Standard Error & T- statistic & Prob. \\
\hline NI & -0.42012 & 0.051783 & -8.1131 & 0.0000 \\
\hline SIZE & -0.06024 & 0.043333 & -1.3901 & 0.1656 \\
\hline GROWTH & -11896.3 & 10854.4 & -1.09599 & 0.274 \\
\hline AGE & 3274.249 & 4793.719 & 0.683029 & 0.4952 \\
\hline DIV & -0.30302 & 0.18935 & -1.60033 & 0.1107 \\
\hline C & 337852.5 & 101810.3 & 3.318451 & 0.001 \\
\hline
\end{tabular}

Results of the Durbin-Watson Test, F statistic, coefficient of determination and adjusted coefficient of determination are as follows

Table 6. Other results of fixed effects- Model Number 2:

\begin{tabular}{|c|c|c|c|c|}
\hline Adjusted R-squared & R-squared & Prob (F-statistic) & F-statistic & Durbin-Watson \\
\hline 0.731194 & 0.801442 & 0.0000 & 11.40877 & 3.424287 \\
\hline
\end{tabular}


In this model, the coefficient of determination is $\cdot / 8$, so $80 \%$ of the changes in the dependent variable are explained by independent variables. Also, the p-value of the F-statistic is zero, so regression is generally significant. Durbin Watson statistic for this model is about 3.4, but due to the use of Arellano covariance, this high statistic is not a problem.

The p-value for the NI variable is zero, so this variable is statistically significant. Also, the coefficient of this variable is -0.42 . That is, for every 100 units of independent variables (NI current year), 42 units of dependent variables (NI next year) decrease.

Considering that in model number 1, the EarnFV variable was statistically meaningless and in contrast to model number 2, the NI variable was statistically significant, so hypothesis number 1 of the research is not supported. So the relationship between fair value-based current earnings and the next year's net income is not stronger than the relationship between Iran's accounting standards-based earnings and the next year's net income.

\section{The second research hypothesis}

Model number 3

$C F_{\mathrm{it}+1}=\beta_{0}+\beta_{1}$ EarnFV $_{i t}+\gamma_{1}$ Size $_{i t}+\gamma_{2}$ Growth $_{i t}+\gamma_{3}$ Div $_{i t}+\gamma_{4} A g e_{i t}+\varepsilon$

The independent variables have one-year lag (t-1):

Table 7. Results of fixed effects- Model Number 3

\begin{tabular}{|c|c|c|c|c|}
\hline Variable & Coefficient & Standard Error & t-statistic & Prob. \\
\hline EARNFV & 0.074177 & 0.043829 & 1.692426 & 0.0917 \\
\hline SIZE & 0.122747 & 0.042571 & 2.883344 & 0.0042 \\
\hline GROWTH & 12184.42 & 12787.3 & 0.952853 & 0.3415 \\
\hline AGE & -2737.3 & 2974.297 & -0.92032 & 0.3582 \\
\hline DIV & -0.06955 & 0.1393 & -0.49929 & 0.618 \\
\hline C & -179850 & 88021.96 & -2.04324 & 0.042 \\
\hline
\end{tabular}

Results of the Durbin-Watson Test, F statistic, coefficient of determination and adjusted coefficient of determination are as follows:

Table 8. Other results of fixed effects- Model Number 3

\begin{tabular}{|c|c|c|c|c|}
\hline Adjusted R-squared & R-squared & Prob(F-statistic) & F-statistic & Durbin-Watson \\
\hline 0.635048 & 0.730422 & 0.0000 & 7.658486 & 3.761162 \\
\hline
\end{tabular}


In this model, the coefficient of determination is $\cdot / 73$, so $73 \%$ of the changes in the dependent variable are explained by independent variables. Also, the p-value of the F-statistic is zero, so regression is generally significant. Durbin Watson statistic for this model is about $r / 8$, but due to the use of Arellano covariance, this high statistic is not a problem.

The p-value for the EarnFV variable is also 0.09, so this variable is statistically meaningless at the level of $5 \%$.

Model Number 4

$C F_{\text {it }+1}=\beta_{0}+\beta_{1} N I_{\text {it }}+\gamma_{1}$ Size $_{i t}+\gamma_{2}$ Growth $_{i t}+\gamma_{3}$ Div $_{i t}+\gamma_{4} A g e_{i t}+\varepsilon$

The independent variables have one-year lag (t-1):

Table 9. Results of fixed effects- Model Number 4

\begin{tabular}{|c|c|c|c|c|}
\hline Variable & Coefficient & Standard Error & t-statistic & Prob. \\
\hline NI & 0.11835 & 0.08566 & 1.381626 & 0.1682 \\
\hline SIZE & 0.127833 & 0.033736 & 3.789203 & 0.0002 \\
\hline GROWTH & 7089.896 & 10863.92 & 0.652609 & 0.5145 \\
\hline AGE & -3032.9 & 2774.893 & -1.09298 & 0.2754 \\
\hline DIV & -0.09484 & 0.152352 & -0.62252 & 0.5341 \\
\hline C & -172348 & 88321.3 & -1.95137 & 0.052 \\
\hline
\end{tabular}

Results of the Durbin-Watson Test, F statistic, coefficient of determination and adjusted coefficient of determination are as follows:

Table 10. Other results of fixed effects- Model Number 4

\begin{tabular}{|c|c|c|c|c|}
\hline Adjusted R-squared & R-squared & Prob (F-statistic) & F-statistic & Durbin-Watson \\
\hline 0.618294 & 0.718046 & 0.0000 & 7.198279 & 3.739953 \\
\hline
\end{tabular}

In this model, the coefficient of determination is $\cdot / N$, so $71 \%$ of the changes in the dependent variable are explained by independent variables. Also, the p-value of the F-statistic is zero, so regression is generally significant. Durbin Watson statistic for this model is about 3.7, but due to the use of Arellano covariance, this high statistic is not a problem.

The $\mathrm{p}$-value for the NI variable is 0.16 , so this variable is statistically meaningless at the level of $5 \%$. 
Considering that in this last two models, the EarnFV and NI variables was statistically meaningless, so hypothesis number 2 of the research is not supported. So the relationship between fair value-based current earnings and next year's cash flows is not stronger than Iran's accounting standards-based earnings and next year's cash flows.

\section{Discussion and Conclusion}

Based on the analysis performed in this study, the first and second hypotheses of the study were not supported. In other words, IFRS-based earnings for SMEs do not predict the future performance of the company better than Iran's standards-based earnings. As previous studies conducted in this field displayed, applying international standards will improve the quality of financial reporting. One of these qualitative characteristics is relevance in decision making. In fact, financial information should be able to help users predict the performance of companies. Results of this study demonstrated that international standardsbased earnings have no better ability to predict the future performance of the company than Iran's standards-based earnings. Both of these earnings are statistically ineffective in predicting cash flows. In other words, while the coefficient of EarnFV was operationally higher than net income in accordance with the standards of Iran (NI) in predicting cash flows and the company's future earnings, both of these variables are statistically insignificant in their respective regression, and are, in fact, incapable of predicting the future performance of SMEs.

It appears that the inability of IFRS-based standards to predict the future performance of the company is due to the low efficiency of the capital market because the theoretical value of a company's stock in the market is calculated based on the future cash flows it generates for shareholders, and in an efficient market, the market price must reflect the company's future cash flows. For example, a company with a high ability to generate cash flows can also divide more cash earnings among its stockholders. According to the standard of Iran, in the case of cash flow in investment companies, investment cash earnings are reported in the operating cash flows sector. If, therefore, the studied market was efficient, the companies' stock market value regarded as fair value should have been better able to predict the operating cash flow. Similarly, company earnings should be of a quality that correlates with operating cash flows. In other words, fair value-based earnings should have been able to predict the company's future earnings as well. The results of this study are consistent with studies of fair value by Sodan (2015) and Rahmani, and Taheri (2018) which 
state that fair value is of low quality. The results are, however, inconsistent with the findings of Senan (2019), Kang \& Yoo (2019), Boina \& Macedo (2018), Bratten, Causholli \& Khan (2016), Yao, Percy, Stewart \& Hu (2015), Cantrell, McInnis \& Yust (2014), Radi \& Pesian (2016), and Radi, Azimi \& Seyyedzadeh (2015) according to which fair value has high predictability.

Funding: This research received no external funding.

\section{References}

Tabrizi Nezhad Malek Mohammad, Zeinab. (2016). Investigating the Relationship between Financial Reporting Quality, Financing and Investment.

Radi, Yasser \& Pesian, Gholamreza. (2016). Investigating the Impact of Fair Value in Financial Reporting on the Predictability of Earnings concerning Future Earnings and Cash Flows in Companies Listed in the Tehran Stock Exchange. The $5^{\text {th }}$ International Conference on Accounting and Management, and the $2^{\text {nd }}$ Conference of Entrepreneurship and Open Innovation.

Radi, Yasser; Azimi, Ahmad \& Farideh, Seyyedzadeh. (2015). Investigating the Impact of Fair Value Use in Financial Reporting on Predicting Future Earnings in Companies Listed in the Tehran Stock Exchange. The $1^{\text {st }}$ International Conference on Management, Economics, Accounting and Education Sciences.

Rahmani, Ali \& and Taheri, Mandana. (2017). Cost Price Versus Facilities' Fair Value: Which one is More Effective in the Credit Loss of Iran's Banking Network? Journal of Monetary-Banking Research, 10 (33), 481-507.

Ball, R., Li, X., \& Shivakumar, L. (2015). Contractibility and Transparency of Financial Statement Information Prepared Under IFRS: Evidence from Debt Contracts Around IFRS Adoption. Journal of Accounting Research, 53(5), 915-963.

Barth, M. E. (2008). Global financial reporting: Implications for U.S. academics. Accounting Review, 83(5), 1159-1179.

Biddle, G. C., Hilary, G., \& Verdi, R. S. (2009). How Does Financial Reporting Quality Relate to Investment Efficiency? Journal of Accounting \& Economics (JAE).

Blankespoor, E., Linsmeier, T. J., Petroni, K. R., \& Shakespeare, C. (2013). Fair value accounting for financial instruments: Does it improve the association between bank leverage and credit risk? Accounting Review, 88(4), 1143-1177.

Boina, T. M., \& Macedo, M. A. da S. (2018). Predictive ability of accruals before and after IFRS in the Brazilian stock market. Revista Contabilidade \& Finanças, 29(78). https://doi.org/http://dx.doi.org/10.1590/1808-057x201806300 
Bonito, A., \& Pais, C. (2018). The macroeconomic determinants of the adoption of IFRS for SMEs. Revista de Contabilidad, 21(2), 116-127.

Bozanic, Z., Roulstone, D. T., \& Van Buskirk, A. (2018). Management earnings forecasts and other forward-looking statements. Journal of Accounting and Economics, 65(1), 1-20.

Bratten, B., Causholli, M., \& Khan, U. (2014). The usefulness of fair values in predicting future cash flows and earnings.

Bratten, B., Causholli, M., \& Khan, U. (2016). The usefulness of fair values for predicting banks' future earnings : Evidence from other comprehensive income and its components ( $\mathrm{P} 21$ ).

Cantrell, B. W., McInnis, J. M., \& Yust, C. G. (2014). Predicting credit losses: Loan fair values versus historical costs. Accounting Review, 89(1), 147-176.

De George, E. T., Li, X., \& Shivakumar, L. (2016). A review of the IFRS adoption literature. Review of Accounting Studies ( ج21).

Evans, M. E., Hodder, L., \& Hopkins, P. E. (2014). The Predictive Ability of Fair Values for Future Financial Performance of Commercial Banks and the Relation of Predictive Ability to Banks' Share Prices. Contemporary Accounting Research, 31(1), 13-44.

Fox, A., Hannah, G., Helliar, C., \& Veneziani, M. (2013). The costs and benefits of IFRS implementation in the UK and Italy. Journal of Applied Accounting Research, 14(1), 86-101.

Hiler, B. A. (1987). The SEC and the Courts' Approach to Disclosure of Earnings Projections, Asset Appraisals, and Other Soft Information: Old Problems, Changing Views, 46(4).

IFRS Foundation. (2018). International Financial Reporting Standard (IFRS). Retrieved from https://www.ifrs.org/issuedstandards/list-of-standards/

IFRS Foundation. (2018). Retrieved from http://ifrs.org

Kang, M., \& Yoo, Y.-T. (2019). Investor perception of fair value evaluation: focusing on financial instruments. Investment Management and Financial Innovations, 16(1). https://doi.org/10.21511/imfi.16(1).2019.16

Liang, L., \& Riedl, E. J. (2014). The effect of fair value versus historical cost reporting model on analyst forecast accuracy. Accounting Review, 89(3), 1151-1177.

Marra, A. (2016). The Pros and Cons of Fair Value Accounting in a Globalized Economy. Journal of Accounting, Auditing \& Finance, 31(4), 582-591.

Pervan, M., \& Visic, J. (2012). Influence of Firm Size on its Business Success. Croatian Operational Research Review, 3. 
Pervan, M., Pervan, I., \& Curak, M. (2017). The Influence of Age on Firm Performance: Evidence from the Croatian Food Industry. Journal of Eastern Europe Research in Business and Economics.

Senan, N. A. (2019). The ability of Earnings and Cash Flows in Forecasting Future Cash Flows : A Study in the context of Saudi Arabia. Academy of Accounting and Financial Studies Journal, 23(1).

Shu, Y., Broadstock, D., \& Xu, B. (2013). The heterogeneous impact of macroeconomic information on firms' earnings forecast. The British Accounting Review, (45), 311-325.

Sodan, S. (2015). The Impact of Fair Value Accounting on Earnings Quality in Eastern European Countries. Procedia Economics and Finance, 32(15), 1769-1786.

Wooldridge, J. M. (2016). Introductory Econometrics A Modern Approach. Cengage Learning. https://doi.org/10.1016/j.jconhyd.2010.08.009

Yao, D., Percy, M., Stewart, J., \& Hu, F. (2015). The Usefulness of Fair Values in Improving the Predictive Ability of Earnings: Evidence from International Banks. AFAANZ Conference. Hobart, TAS. Retrieved from https://eprints.qut.edu.au/95456/

\section{Bibliographic information of this paper for citing:}

Seddighi, Roohollah; Ghasemi, Ali \& Momenzadeh, Mohammad Mehdi (2021). The Effect of Using Fair Value Approach on Performance Prediction in Investment Companie. Iranian Journal of Finance, 5(2), 1-20.

Copyright @ 2021 , Roohollah Seddighi, Ali Ghasemi and Mohammad Mehdi Momenzadeh 